Akdeniz Eğitim Araştırmaları Dergisi

Mediterranean Journal of Educational Research 2020, Cilt 14 Say1 32, Sayfa 78-97

https://doi.org/10.29329/mjer.2020.258.5

Copyright (C) 2020. Açık Erişim Makale CC BY-NC-ND

\title{
5-6 Yaş Çocukları için 21. Yy Becerileri Ölçeği (DAY-2): Geçerlik ve Güvenirlik Çalıșması
}

\author{
Vakkas Yalçın ${ }^{1}$, Ahmet Simsar ${ }^{2}$, \& Hızır Dinler ${ }^{3}$
}

Özet: Bu araştırmanın amacı, 5-6 yaş çocuklarının 21.yy becerilerine yönelik bir ölçme aracı geliştirmek, geçerlilik ve güvenilirlik sonuçlarını ortaya koymaktır. Ölçek geliştirme çalışmalarında izlenen süreç (alan yazın taranması, madde havuzunun oluşturulması, taslak ölçeği uzmanlara verilmesi, ön deneme, yapı geçerliliğinin belirlenmesi) dikkate alınarak taslak ölçeğe son biçimi verilmiştir. Ölçeğin yapı geçerliliğini belirlemek için 5-6 yaş grubunda 317 çocuktan elde edilen verilerle açımlayıcı ve 305 çocuktan elde edilen verilerle doğrulayıcı faktör analizi gerçekleştirilmiştir. Açımlayıcı ve Doğrulayıcı analizlerin gerçekleştirilmesi için sosyal bilimlerde kullanılan SPSS ve Mplus 7 programları kullanılmıştır. Açımlayıcı faktör analizi sonucunda ölçekte 33 madde kalmıştır ve bu maddeler Yaşam ve Kariyer Becerileri, Öğrenme ve Yenilik Becerileri (4Cs), Bilgi-Medya ve Teknoloji Becerileri olmak üzere üç faktör altında toplanmıştır. Yapılan doğrulayıcı analizler sonucunda, ölçeğin 33 maddeden oluştuğu doğrulayıcı faktör analizinin uyum belirteçleri olan RMSEA, CFI, TLI ve WRMSR gibi değerlerden yararlanılarak, ölçeğin kuramsal ve istatistiksel olarak uygun saptanmıştır. Güvenirliğin belirlenmesine yönelik olarak Cronbach Alpha $(\alpha)$ değerlerine bakıldığında ise ölçeğin Öğrenme ve Yenilik Becerileri (4Cs) boyutu için .96, Yaşam ve Kariyer Becerileri boyutu için .94 ve Bilgi, Medya ve Teknoloji Becerileri boyutu için .92 olarak hesaplanmıştır. Ölçeğin tek boyutlu halinin Cronbach Alpha $(\alpha)$ scoru .97 gibi yüksek bir değer olarak hesaplanmıştır. 5-6 Yaş Çocukları için 21. Yüzyıl Becerileri ölçeğinin; 33 maddeden oluştuğu, açımlayıcı ve doğrulayıcı faktör analizinin uyum belirteçleri ile belirlenmiş, DAY-2 ölçeğinin kuramsal ve istatiksel açıdan geçerli ve güvenilir bir ölçek olduğu ortaya konulmuştur.

Anahtar Kelimeler: 21. yy Becerileri, 5-6 Yaş, Okul Öncesi, Erken Çocukluk Eğitimi

Geliş Tarihi: 30.03.2020 - Kabul Tarihi: 04.06.2020 - Yayın Tarihi: 29.06.2020

DOI: $10.29329 /$ mjer.2020.258.5

\section{1st Century Skills Scale for Children 5-6 Years (DAY-2): Validity and Reliability Study}

Abstract: The aim of this study is to develop a measurement tool for the 21st century skills of 5-6 year old children and to reveal the validity and reliability results. The draft scale was finalized by taking into account the process followed in the scale development studies (scanning the literature, creating the item pool, giving the

\footnotetext{
${ }^{1}$ Vakkas Yalçın, Research Assist, Okul Öncesi Eğitimi Ananilim Dalı, Muallim Rıfat Eğitim Fakültesi, ORCID: 0000-00028571-9203

Correspondence: vakkasyalcin@kilis.edu.tr

${ }^{2}$ Ahmet Simsar, Assist. Prof., Muallim Rifat Eğitim Fakültesi, Kilis 7 Aralık Üniversitesi, ORCID: 0000-0002-4335-8788

${ }^{3}$ Hızır Dinler, Research Assist, Temel Eğitim Bölümü, Kilis 7 Aralık Üniversitesi, ORCID: 0000-0003-3144-6649
} 
draft scale to the experts, pre-experiment, determining the validity of the structure). In order to determine the construct validity of the scale, exploratory factor analysis was performed with data from 317 children in the 5-6 age group. Confirmatory factor analysis were calculated with data from 305 children. SPSS and Mplus 7 programs used in social sciences were used to perform exploratory and confirmatory analyzes. As a result of exploratory factor analysis, 33 items remained on the scale and these items were gathered under three factors: Life and Career Skills, Learning and Innovation Skills (4Cs), Information-Media and Technology Skills. As a result of the confirmatory factor analysis, the scale was found to be theoretically and statistically reliable by using the values such as RMSEA, CFI, TLI and WRMSR, which are the determinants of the confirmatory factor analysis. When looking at Cronbach Alpha $(\alpha)$ values for determining reliability, it was calculated as .96 for Learning and Innovation Skills (4Cs) dimension, .94 for Life and Career Skills dimension and .92 for Information, Media and Technology Skills dimension. The one-dimensional version of the scale was calculated as a high value such as Cronbach Alpha $(\alpha)$ score .97. It was determined that the DAY-2 scale was a theoretically and statistically valid and reliable scale.

Keywords: 21st Century Skills, 5-6 Years, Preschool, Early Childhood Education

\section{GíRiş}

21.Yüzyıldaki toplumsal, ekonomik, siyasi ve özellikle de teknolojik değişim sonucunda ve bu gelişmelere bağlı olarak ihtiyaç duyulan bireylerin niteliklerinde de bir takım değişiklikler göze çarpmaktadır. Dolayısıyla farklı alanlardaki bu gelişmeler ihtiyaç duyulan nitelikli bireylerin ortaya çıkmasını sağlayacak eğitim sistemlerini etkilemekte ve ülkelerin eğitim politikalarında bir takım değişimler yapmalarını zorunlu hale getirebilmektedir (Kenan, 2005). Önceleri bilgiye ulaşmak çok daha önemli görülürken, günümüzde bilgiden ziyade bilginin anlamlandırılması, kullanabilmesi, önemli bilgiyi ayırt edebilmesi ve diğer bilgilerle ilişkilendirilmesi birey için daha önemli beceriler haline gelmiştir (Harari, 2018).

Ananiadou ve Claro (2009), bireylerin okullarda ve hayatta kazanmaları gereken temel beceri ve yeterliklerin önemli olduğunu vurgulamaktadır. $\mathrm{Bu}$ beceriler; karmaşı problem çözme becerisi, analitik ve eleştirel düşünme becerileri, yenilikçilik, yönetim becerileri, iletişim/etkileşim becerileri, duygusal zekâ ve karar alma becerileri, hizmet odakl11ık, bilişsel esneklik becerileri olarak sıralanabilir (Gray, 2016). Bu doğrultuda, okullarda teknik bilgi ve becerilerden ziyade yaşadığı zamana ayak uydurabilecek ve zamanı yönlendirebilecek yaşam becerilerine sahip bireylerin yetişmesi oldukça önemlidir.

21.Yy becerileri, farklı kurum ve kuruluşlar tarafından farklı sayılarda ve isimlerle sıralansa da bu beceriler birbiriyle ortak ve birbirini destekler niteliktedir. Bunlardan National Research Council [NRC] (2011) 2005-2009 yıllarında yaptığı bir takım çalışmalarla 21. yy becerilerini üç boyutta ifade etmiştir. Bunlar; olaylar hakkında bir yargılama yapma ve karar verme, analiz ve değerlendirmenin yanı sıra, soyut akıl yürütmeyi içeren bilişsel beceriler (Peterson ve diğ., 1999 dan akt., National 
Research Council (2011), insanları etkin dinleme, sözel ifadeleri etkili şekilde iletme, sözel olmayan iletişim araçlarını etkili şekilde kullanma, iletişim ve işbirliği becerisini kullanarak organizasyon yapabilme, güven duyma ve oluşturma, farkl11ıkları anlama ve farklılıklara sayg1lı olma, farklı düşüncelere saygı duyma ve insanlar üzerinde sosyal etki oluşturmayı içeren kişiler arası beceriler (National Research Council, 2011) ve son olarak, kendi kendini yönetebilen, öz disiplinli, öz denetimi yüksek, kendini geliştirme becerisine sahip, zamanını yönetebilme becerisini içeren içsel becerilerdir (National Research Council, 2011).

Öte yandan, Kuzey Merkez Bölgesel Eğitim Laboratuarı (The North Central Regional Educational Laboratory-NCREL) (2003) yaptığı çalışmalarla 21.yy becerilerini, küreselleşme ve dijitallik başlıkları altında; evrensel okuryazarlık, yaratıcılık, iletişim becerileri ve verimlilik şeklinde dört bölüme ayırmıştır (EnGauge, 2003). Evrensel okuryazarlık, bireyin kendi dilini, matematiği, bilimi anlayabilmesi, medya ve iletişim araçlarını öğrenme amaçlı kullanması, değişik kültürel özellikleri anlaması ve evrensel düzeyde sorunları anlayabilmesi şeklinde ifade edilirken, yaratıcılık; karmaşık problemlere çözüm getirebilmesini, belirlenen hedefler doğrultusunda çalışmalar yürütebilmesini, risk alabilmesini ifade etmektedir. İletişim becerileri ve verimlilik ise gruplar halinde çalışmalar yürütebilmeyi, teknolojiyi kullanabilmeyi ifade etmektedir (EnGauge, 2003).

Araştırmacılara göre 21.yy becerileri üzerinde en çok çalışma yürüten kuruluşlardan biri de Partnership for 21st Century Skills (P21) dir (Göksün ve Kurt, 2017). Çalışmalar bu becerilerin ilerleyen zamanlarda iş ve meslek alanlarında ihtiyaç duyulan yeterlik ve özellikleri etkilediğini göstermektedir (Voogt ve Roblin, 2012). Bundan dolayı P21'de, okul öncesinden başlanarak diğer eğitim kademelerindeki çocukların sahip olması gereken becerilere değinilmiştir. 21. yy becerileriyle ilgili alanyazın incelendiğinde P21'in belirlediği beceriler çerçevesi oldukça kabul görmüş ve referans alınmıştır (Beers, 2011; Brown, 2018; Gelen, 2017; Lamb ve diğerleri, 2017; Partnership for 21st Century Skills, 2018a; 2018b; 2015; 2009). Bu bağlamda çalışmanın genel çerçevesi oluşturulurken P21'in belirlediği 21.yy becerileri de dikkate alınmıştır.

\section{Problem durumu}

2000’li yılların başlamasıyla birlikte 21.yy beceriyle ilgili yapılan çalışmalarda ortaya çıkmaya başlamıştır (Gökçe, 2000; Pedro, 2006; Prensky, 2001a; 2001b; 2003). Bu doğrultuda yurtdış1 alanyazın incelendiğinde, Mardis ve Dickinson'ın (2009) bilgi ve medya uzmanlarının 21. yу. öğrenenlerine ilişkin algılarını araştırdıkları çalışmalarına, Herring ve Notar (2011) ile Partnership ve EnGuage tarafından tanımlanan 21. yy. becerileri çerçevesinde, eğitimde e-portfolyo kullanımına yönelik çalışmalarına, Young (2012) 21. yy. öğrenen becerileri ve medya okuryazarlığı bağlantısını ortaya koymaya çalıştığı araştırmasına, Williams, Gannon ve Sawyer'ın (2013) Avustralya bağlamında 21. yy. öğrenen becerilerini belirlemeye çalıştıkları araştırmalarına ve Woods-Grooves'un 
(2015) 21. yy. öğrenenlerinin davranışlarını etkileyen faktörlerin belirlenmesini amaçladığı çalışmalar göze çarpmaktadır.

Bununla birlikte yurtiçi alanyazın incelendiğinde, Göksün ve Kurt (2017)'un öğretmen adaylarının 21. yy. öğrenen becerileri kullanımları ve 21. yy. öğreten becerileri kullanımları arasındaki ilişkiyi incelediği çalışma, Şahin (2010)'in, öğretmen adaylarının yeni yüzyılın öğrencisi olma durumunun farklı değişkenlere (cinsiyetleri, öğrenim gördükleri sınıf düzeyi, alan ve üniversitelere) göre incelediği araştırmaya, Thomas (2014)'ın üniversiteye hazırlık öğrencileri, öğretmen ve yöneticilerle yürüttüğü ve yükseköğretime hazırlıkları sırasında 21. yy. öğrenen ihtiyaçlarının karşılanıp karşılanmadığını belirlemeye çalıştığı araştırmalar yer almaktadır.

Öte yandan yurt içi alan yazında bireylerin 21.yy becerilerini ölçmeye yönelik geçerlik güvenirlik çalışması yapılmış oldukça az ölçme aracı yer almaktadır. 21.yy. becerilerine yönelik ölçme araçlarıyla ilgili yapılan literatür taramasında, Çevik ve Şentürk (2019), 15-25 yaş çocuk ve gençlerle yapmış olduğu “çok boyutlu 21. yy becerileri ölçeğii” ve Aygün, Atalay, Kılıç ve Yaşar (2016)'ın, “öğretmen adaylarına yönelik 21. yüzyıl becerileri yeterlilik algıları ölçeği” ne rastlanmaktadır. Buna karşılık okul öncesi çocuklarının 21. yy becerileni ölçmeye yönelik herhangi bir ölçme aracına rastlanılmamıştır.

Ayrıca okul öncesi düzeyde yapılan konu ve içeriği 21.yy. becerileri ve STEM (Science, Technology, Engineering \& Mathematics) olan araştırmalar incelendiğinde; genellikle görüşme ve gözlem formu kullandıkları ve çalışmalarını nitel desende (Akgündüz, ve Akpınar, 2018; Ceylan, 2014; Özçelik ve Akgündüz, 2018; Uğraş, 2017) kurguladıkları veya söz konusu konularda derleme çalışmalar (Çi1, 2018; Tuğluk ve Özkan, 2019; Yalçın, 2019) olduğu görülmüştür. Buna karş1lık okul öncesi düzeyde nicel araştırma yürütebilecek geçerliği ve güvenirliği yapılmış bir ölçme aracına rastlanılmamıştır.

\section{Araştırmanın Önemi}

Evrensel okuryazarlığın artması için bireylerde 21.yy. becerilerinin geliştirilmesi oldukça önem arz etmektedir. Bu becerilerin bireylerde geliştirilmesindeki önemli noktalardan birisi, okul öncesi dönemden başlanarak diğer eğitim kademelerinde de desteklenmesidir. Bununla birlikte bu becerilerin kazanılmasına ve geliştirilmesindeki önemli etkenlerden birisi de doğru ölçme araçlarıyla bu becerilerin belirli aralıklarla ölçülmesi, kontrol edilmesi ve bu doğrultuda aile, öğretmen ve eğitim programcılarına doğru çıktıların verilmesidir. Alan yazın incelendiğinde bu becerilerin ölçülme yaşı lise ve üniversite seviyesinde (Çevik ve Şentürk 2019; Aygün, Atalay, Kılıç ve Yaşar, 2016) olduğu ancak yaşamsal becerilerin kazanılmasında hayati önem taşıyan okul öncesi döneme yönelik olarak bu becerileri ölçecek bir araca yapılan alan yazın taramasında rastlanmamıştır. Bu bağlamda okul öncesi çocuklarının 21. yy becerilerini belirlemeye yönelik yapılan "5-6 Yaş Çocukları için 21.yy. Becerileri Ölçeği (DAY-2)" alanyazında var olan açığı kapatacağından çalışma oldukça önemli görülmektedir. 


\section{YÖNTEM}

“5-6 Yaş Çocukları için 21. Yy. Becerileri Ölçeği (DAY-2)” ölçeğinin geçerlik ve güvenirlik çalışmasının yapıldığı bilimsel bir araştırma olan bu çalışmada, örneklem grubunun demografik özellikleri ve ölçek geliştirilme aşamaları aşağıda sunulmuştur.

\section{Çalışma Grubu}

Araştırmanın örneklem grubunu, 5-6 yaş okul öncesi grubundan 622 çocuk oluşturmaktadır. Veriler 12 farklı anaokulunda bulunan 36 okul öncesi öğretmenine sinıflarında bulunan çocuklar için ilk aşamada açımlayıcı faktör analizi için 427 form, ikinci aşamada doğrulayıcı faktör analizi için 420 form olmak üzere toplamda 847 form dağıtılmıştır. Öğretmenler formları her bir çocuk için doldurmadan önce ölçek formunda geçen maddeleri okumaları ardından, çocukları 4 hafta gözlemleyerek bu süreç içerisinde doldurmaları istenmiştir. Bu süre sonunda ilk aşamada dağıtılan 427 ölçek formundan, 330 form için geri dönüş olmuş ve bunlardan 13 eksik veya yanlış doldurulduğu için çıkartılmıştır. Son durumda açımlayıcı faktör analizi için 317 ölçek formu kullanılmıştır. İkinci aşama için dağıtılan 420 ölçek formundan, 310 form için geri dönüş olmuş ve bu ölçek formlarından beşi öğretmenler tarafından eksik veya yanlış doldurulduğundan çalışmaya dahil edilmemiştir. Son durumda çalışmanın ikinci aşaması için 305 ölçek formu kullanılarak çalışma yürütülmüştür. Çocuklara ve ailelerine ait demografik bilgiler Tablo 1 de verilmiştir.

Tablo 1. Çocuklara ve ailelerine ait demografik bilgiler

\begin{tabular}{llcc}
\hline Tema & Kod & f & $\%$ \\
\hline \multirow{2}{*}{ Cinsiyet } & Kız & 318 & 51,13 \\
& Erkek & 304 & 48,87 \\
\hline \multirow{2}{*}{ Uyruk } & Türkiye & 560 & 90,03 \\
& Diğgr & 62 & 9,97 \\
\hline \multirow{4}{*}{ Ev Hanımı } & 353 & 56,75 \\
& Öğretmen & 84 & 13,50 \\
& Hemşire & 13 & 2,09 \\
& Memur & 12 & 1,93 \\
Mesleği & Polis & 5 & 0,80 \\
& İşçi & 4 & 0,64 \\
& Doktor & 3 & 0,48 \\
& Öğretim Üyesi & 1 & 0,16 \\
& Diğer (İsssiz, Serbest Meslek, Kuaför, Mühendis, Sekreter...) & 57 & 9,16 \\
& Belirtilmemiş & 90 & 14,47 \\
\hline & Esnaf & 56 & 9,00 \\
& Öğretmen & 53 & 8,52 \\
& Serbest Meslek & 47 & 7,56 \\
& İşçi & 36 & 5,79 \\
& Memur & 30 & 4,82 \\
Babanı̆ & Güvenlik Görevlisi & 11 & 1,77 \\
Mesleği & Tamirci & 11 & 1,77 \\
& İşiz & 11 & 1,61 \\
& Şoför & 10 & 1,61 \\
& Askeri Personel & 10 & 1,45 \\
& Fabrika İşçisi & 9 & 0,96 \\
& Bankacı & 6 & 0,80 \\
& Boyacı & 5 & 0,80 \\
\hline
\end{tabular}




\begin{tabular}{lcc}
\hline Doktor & 5 & 0,80 \\
Çiftçi & 4 & 0,64 \\
Diğer (Emekli, Kuaför, Fırıncı, simitçi, Bekçi..vb) & 169 & 27,17 \\
Belirtilmemiş & 155 & 24,92 \\
\hline
\end{tabular}

Araştırmaya katılan çocuklardan yaklaşık olarak yarısı $(\% 51,13)$ kız çocuklardan oluşmaktadır. Çocukların büyük çoğunluğu Türkiye vatandaşı $(\% 90,03)$ olup çok az bir kısmı diğer şeklinde (Suriye, Afgan, Türkmen, vb) belirtilmiştir. Araştırmada verilerin toplanması sürecinde her türlü sosyo ekonomik düzeydeki okullara ulaşılmaya çalışılmıştır. Bunun sonucu olarak Tablo 1 de çok farklı aile yapılarının olduğu gözlenmektedir. Anne mesleğine bakıldı̆̆ında, farklı meslek gruplardan annelerin çocuklarına ulaşıldığı görülmektedir. Araştırmada yer alan çocukların annelerin büyük çoğunluğu $(\% 56,75)$ ev hanımı olarak belirtilirken, daha sonra öğretmen $(\% 13,50)$ olduğu görülmektedir. Benzer şekilde babanın mesleki durumuna bakıldığında, en fazla esnaf $(\% 9,00)$ ve öğretmen $(\% 5,52)$ olduğu gözlenmektedir. Bunların yanı sıra farklı mesleki gruplardan babaların çocuklarında araştırmaya katıldığ görülmektedir.

\section{Ölçeğin Geliştirilme Süreci}

DAY-2 ölçeğinin geliştirilmesi surecinde ilk aşamada alan yazın taraması yapılarak çocuklarda 21. yy becerileri belirlenmeye çalışı1mıştır (Şekil 1). Bu kapsam yurt içi ve yurt dışı tarama çalışmalarının yanı sıra Milli Eğitim Bakanlığı Okul Öncesi Eğitim Programında (2013) yer alan ve çocukların farklı alanlardaki (bilişsel, dil, sosyal-duygusal, fiziksel ve öz bakim) becerileri incelenerek çocuklardaki gelişimsel dönemlerine uygun ve okul öncesi öğretmenlerin çocuklarda gözlemleyebilecekleri uygun ifadeler belirlenmiştir. Ayrıca 21. yy becerilerine yönelik olarak şimdiye kadar yurtiçi ve yurtdışında hazırlanmış benzer araştırmalar taranmış ve bu araştırmalarda kullanılan veri toplama araçları incelenmiştir. Yapılan kaynak taraması sonucunda ölçekte kullanılan ifadeler belirlenmiş ve ölçme aracı ile ilgili teorik alt yapı oluşturulmuştur. Elde edilen veriler doğrultusunda "yaşam ve kariyer becerileri", "öğrenme ve yenilik becerileri (4Cs)" ve "bilgi-medya ve teknoloji becerileri" olmak üzere 3 alt boyuttan oluşan 78 maddelik soru havuzu oluşturulmuştur. Tezbaşaran, (1996) ölçek tasarlama sürecinde ölçekte kullanılması planlanan madde sayısının mümkün olduğunca fazla olması gerektiğini ve istenildiği durumda olumsuz yargılara da yer verilebileceğini belirtmiştir. Bu çalışmada da 78 maddelik soru havuzu oluşturulmuş ve tüm maddeler bir formda toplanarak, 2 Türkçe dil uzmanına, 5 okul öncesi eğitim uzmanına, 3 ölçme ve değerlendirme uzmanına gösterilmiştir. Uzmanlardan maddelerin ölçek için uygunluğuna ilişkin cevaplarını 3'lü derecelendirme ölçeği (1: Kaldırılmalı, 2: Revize edilmeli, 3: Kalmalı) üzerinde belirtmeleri istenmiş̧ir. Uzmanlardan gelen formlar toplandıktan sonra, tüm cevaplar tek bir formda birleştirilmiştir. Bu süreç içerisinde uzmanların her bir maddeye yönelik vermiş oldukları dönütler ve oluşturulan ilgili teori sonucunda maddeler düzenlenmiştir. Ayrıca elde edilen veriler değerlendirilirken maddelerin kapsam geçerliği için Veneziano ve Hooper (1997) tarafindan 
geliştirilen kapsam geçerlik oranı (KGO) ile belirlenmiştir. Araştırmacılara göre KGO her bir madde için olumlu yanıt vermiş uzman sayısı toplamının toplam uzman sayısına oranının bir eksiği alınarak belirlenmiştir (Veneziano ve Hooper, 1997). Bu oran kapsamında .80'in altında değer alan maddeler ölçekten çıkartılarak 56 maddelik ve "Hiçbir zaman”, "Nadiren”,"Genellikle” ve "Her zaman” 4’lü Likert formatında son hali verilmiştir. Genel uygulamalara geçilmeden önce 56 maddelik ölçek araştırmaya dahil edilmeyen 5 okul öncesi öğretmenine ( 2 anasınıfı, 3 anaokulu) gönderilerek bir pilot uygulama gerçekleştirilmiştir. Pilot uygulama sonrasında geri gelen olumlu dönütler doğrultusunda maddelerin son hali çocuklara ait demografik formlar oluşturularak genel uygulamaya geçilmiştir.

- Yurt içi ve Yurt dişı

kaynakların incelenmesi

- MEB (2013) okul öncesi

eğitim programının

incelenmesi

- 21 YY becerilerine yönelik

lise, üniversite vb. farklı

yaş gruplarındaki diğer

ölçeklerin incelenmesi

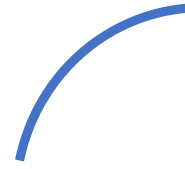

Uzman Görüşüne

\section{Sunulması}

- Ölçekte kullanılan

Faktörlerin belirlenmesi,

- Soru havuzunun

oluşturulması

- Uzman Görüşüne

Sunulması
- Uzman görüşlerine yönelik ölçeğin düzenlenmesi

- 56 Maddelik ve 4 lü likert tipi

ölçeğin oluşturulması

- Pilot uygulama Yapılmasi

- Pilot uygulama sonucunda soruların anlaşılırlılığı üzerine son düzeltmelerin yapılması

- Ölçeğin Son halinin verilmesi

- Verilerin toplanması ve AFA

analizlerinin yapılması

- DFA için verilerin toplanıp

analizlerin yapılması

\section{DAY-2 Ölçeği}

Şekil 1. Ölçeğin geliştirilme süreci

\section{Verilerin Toplanması}

56 maddelik ve 4"lu Likert formatında oluşturulan DAY-2 ölçeğinin son hali 12 farklı anaokulunda bulunan 36 okul öncesi öğretmenine sınıflarında bulunan çocuklar için ilk aşamada açımlayıcı faktör analizi için 427 form, ikinci aşamada doğrulayıcı faktör analizi için 420 form olmak üzere toplamda 847 form dağıtılmıştır. Öğretmenler formları her bir çocuk için doldurmadan önce ölçek formunda geçen maddeleri okumaları ardından, çocukları 4 hafta gözlemleyerek bu süreç içerisinde doldurmaları istenmiştir. Bu süre sonunda ilk aşamada dağıtılan 427 ölçek formundan, 330 form için geri dönüş olmuş ve bunlardan 13 eksik veya yanlış doldurulduğu için çıkartılmıştır. Son durumda açımlayıcı faktör analizi için 317 ölçek formu kullanılmıştır. İkinci aşama için dağıtılan 420 ölçek formundan, 310 form için geri dönüş olmuş ve bu ölçek formlarından beşi öğretmenler tarafından eksik veya yanlış doldurulduğundan çalışmaya dâhil edilmemiştir. Son durumda çalışmanın ikinci aşaması için 305 ölçek formu kullanılarak çalışma yürütülmüştür. 


\section{Verilerin Analizi}

Ölçeğin kapsam geçerliliğinin sağlanılması için 2 Türkçe dil uzmanı, 5 okul öncesi eğitim uzmanı ve 3 ölçme ve değerlendirme uzmanı olmak üzere toplamda 10 farklı alanınında doktora derecesine sahip uzman görüşüne başvurularak ölçeğin son hali verilmiştir. Ölçeğin yapı geçerliliğinin belirlenebilmesi için okul öncesi öğretmenlerinin görüşlerine başvurulmuş ve soruların nasıl anlaşıldığı incelenmiştir. İstatistiksel olarak ayrıca yapı geçerliliğine yönelik olarak SPSS ve Mplus programlarından yararlanılarak ölçeğin açımlayıcı faktör analizi (AFA) ve doğrulayıcı faktör analizleri (DFA) yapılarak ölçeğin geçerliliğine ilişkin istatistiksel kanıtlar sunulmuştur. AFA analizi, yorumlanması güç olan, birbirleriyle korelasyonu olan maddeleri yapısal olarak anlamlı ve nispeten bağımsız faktörler altında toplayan çok değişkenli bir analiz yöntemidir. AFA analizinde amaç birden fazla maddenin bir araya gelerek anlamlı yapılar oluşturabilmesi olarak belirtilmiştir (Büyüköztürk, 2002; Tezbaşaran, 1996; Yıldırım, 1999).

Katılımcı sayısına yönelik olarak bu çalışmada katılımcı sayısı ölçekte yer alan madde sayısına göre belirlenmiştir $\left(56^{*} 10=560\right)$. Araştırmacılar ölçek geliştirme sürecinde katılımcı sayısının ölçek te yer alan madde sayısının 5 ila 10 katı arasında olabileceğini belirtmişlerdir (Kline, 1994; Tavşancıl, 2014). Benzer olarak Çokluk, Şekercioğlu ve Büyüköztürk (2012) bir ölçeğe yönelik faktör analizi yapılabilmesi için katılımcı sayısının en az 300 olmasının uygun olduğunu belirtmiştir. Bu çalışmada AFA analizi için 317 ve DFA analizi için 305 veri seti kullanılmıştır.

AFA analizi ve DFA analizi için veriler belirlendikten sonra Cronbach alfa, Kaiser-Meyer-Olkin (KMO) ve maddelerin faktörlenebilirliğini test etmek için ise Barlett testi SPSS 23 programı kullanılarak test edilmiştir. Ölçeğin yapı geçerliğini belirlemek amacıyla MPlus (Muthen ve Muthen, 1998-2012) kullanılarak Geomin eğik döndürme metodu kullanılmış (Tavşancıl, 2006) ve AFA temel bileşenler analizi yapılmıştır. AFA analizinde faktör yükleri en az .30 olarak belirlenmiş ve .30 'un altındaki maddeler ölçekten çıkartılmıştır (Büyüköztürk, 2012). Ölçeğin alt boyutları ve toplam güvenirlikleri için Cronbach alfa katsayıları ve Pearson Momentler Çarpımı Korelayon Katsayısı hesaplanarak ölçeğin güvenirliliğinin test tekrar test yöntemi kullanılarak ortaya konulmuştur. Ayrıca AFA analizi sonucunda ortaya konulan yapının doğruluğunun test edilebilmesi için iki farklı boyutta DFA analizleri yapılmıştır.

\section{BULGULAR}

Bu bölümde öncelikli olarak AFA analizine ilişkin bulgulara, daha sonra birincil düzeyde DFA ve ikincil düzey DFA analizlerine ilişkin bulgulara yer verilmiştir.

\section{Açımlayıcı Faktör Analizine İlişskin Bulgular}

Ölçeğin yap1 geçerliğini ortaya koyabilmek için maddelerin faktör yüklerinin boyutlandırabilmek amacıyla ilk olarak AFA analizi yapılmıştır. Tavşancıl (2010)'a göre faktör analizinde, örneklemden elde edilen verilerin yeterliğini belirlemek için Kaiser-Meyer-Olkin (KMO) 
testi yapılmalıdır. Aynı şekilde Çokluk, Şekercioğlu ve Büyüköztürk (2012 ) verilerin AFA analizine uygun olup olmadığını belirlemek için KMO ve Barlett Sphericity testi yapılması gerektiğini belirtmiştir. Verilerin AFA analizine uygunluğunu test etmek amacıyla ilk olarak KMO değeri .96 olarak hesaplamış ve Barlett test değeri 17415.15, $\mathrm{p}<.001$ olarak anlamlı bulunmuştur (George ve Mallery, 2001). KMO bulunan değerin 1'e yaklaştıkça mükemmel, 0.50'nin altında ise kabul edilemeyeceğini göstermektedir (George ve Mallery, 2001). Buna göre çalışmadaki verilerin faktör analizleri için mükemmel bir şekilde uygun olduğu söylenebilir.

Çalışmada açımlayıcı faktör analizi yapılabilmesi için Mplus 7 programından yararlanılmış ve (AFA) sonuçlarına göre üç (3) faktörlü modelin veri seti ile en iyi uyum gösteren model olduğu saptanmış ve Geomin eğik döndürme işlem sonucunda elde edilen faktör yükleri Tablo 2 de gösterilmiştir. Üç faktörlü yapıya ilişkin elde edilen istatistikler $X^{2} / \mathrm{sd}=2.66, \mathrm{RMSEA}=.06, \mathrm{CFI}=.91$, $\mathrm{TLI}=.90$ ve $\mathrm{SRMR}=.04$ olarak bulunmuştur.

Tablo 2. DAY-2 Ölçeğinin AFA Döndürülmüş Faktör Yükleri

\begin{tabular}{lccc}
\hline Madde & 1. Boyut & 2. Boyut & 3. Boyut \\
\hline M1 & $0.83^{*}$ & 0,09 & 0,20 \\
M2 & $0.89^{*}$ & 0,14 & 0,12 \\
M3 & $0.94^{*}$ & 0,19 & 0,13 \\
M5 & $0.87^{*}$ & 0,26 & 0,19 \\
M6 & $0.84^{*}$ & 0,25 & 0,23 \\
M7 & $0.5^{*}$ & 0,14 & 0,28 \\
M9 & $0.89^{*}$ & 0,12 & 0,27 \\
M10 & $0.93^{*}$ & 0,22 & 0,23 \\
M11 & $0.93^{*}$ & 0,18 & 0,25 \\
M12 & $0.86^{*}$ & 0,22 & 0,27 \\
M13 & $0.70^{*}$ & 0,23 & 0,22 \\
M14 & $0.85^{*}$ & 0,23 & 0,29 \\
M15 & $0.77^{*}$ & 0,29 & 0,18 \\
M16 & $0.97^{*}$ & 0,18 & 0,11 \\
M18 & $0.90^{*}$ & 0,22 & 0,27 \\
M27 & 0,27 & $0.79^{*}$ & $-0,01$ \\
M28 & $0.69^{*}$ & 0,09 \\
M31 & $0.61^{*}$ & 0,10 \\
M40 & 0,38 & $0.71^{*}$ & 0,17 \\
M41 & $0.36 *$ & 0,18 \\
M42 & 0,28 & $0.86^{*}$ & 0,22 \\
M43 & 0,29 & $0.86^{*}$ & 0,23 \\
M44 & $0.62^{*}$ & 0,20 \\
M45 & $0.67^{*}$ & 0,28 \\
M47 & 0,33 & 0,38 \\
M48 & 0,37 & $0.72^{*}$ & 0,28 \\
M50 & 0,31 & 0,22 \\
M51 & $0.65^{*}$ & 0,23 \\
M52 & $0.85^{*}$ & $0.65^{*}$ \\
M53 & 0,29 & $0.66^{*}$ \\
M54 & 0,20 & $0.74^{*}$ \\
M55 & 0,20 & $0.66^{*}$ \\
M56 & 0,26 & $0.64^{*}$ \\
\hline 05 & 0,22 & 0,16 &
\end{tabular}

*.05 düzeyinde istatistiksel olarak anlamlı 
Tablo 2'de döndürülmüş 56 maddeye ilişkin faktör yüklerine bakıldığında birinci faktör için belirtilen 26 maddeye yönelik olarak istatistiksel olarak anlamlı bir şekilde yüklenme yapmayan veya .40 ve altında yüklenme yapan maddelerin (madde 4, madde 8 , madde 17, madde 19, madde 20, madde 21 , madde 22 , madde 23 , madde 24 , madde 25 ve madde 26) ölçekten çıartılmasına karar verilmiştir. Benzer olarak ikinci faktör için belirlenen 25 madde içerisinden ikinci faktöre yönelik olarak istatistiksel olarak anlamlı bir şekilde yüklenme yapmayan veya .40 ve altında yüklenme yapan maddelerin (madde 29, madde 30, madde 32, madde 33, madde 34, madde 35, madde 36, madde 37, madde 38 ve madde 39) ölçekten çıkartılmasına karar verilmiştir. Çalışmada son olarak üçüncü faktör için belirlenen 5 maddeye yönelik olarak istatistiksel olarak anlamlı ve .40 üzerinde etkiye sahip olan maddelerin ölçekte kalmasına karar verilmiştir. Her bir faktöre yükleme yapan maddeler incelendiğinde, birinci faktör ögrenme ve yenilik becerileri (4Cs), ikinci faktör yaşam ve kariyer becerileri ve üçüncü faktör bilgi, medya ve teknoloji becerileri olarak adlandırılmıştır. AFA sonucunda ölçekte kullanılan bazı örnek sorular aşağıdaki gibidir.

M1: Hikâye anlatırken ya da duygularını ifade ederken farklı araçları (beden dili, drama, müzik, resim vb.) dener.

M2: Bloklardan bina yaparken veya aklındakini kâğıda aktarırken fikirlerini yaratıcı şekilde ifade eder.

M18: Bir problemi çözmek için sorular sorar ve arkadaşlarını sürece dâhil eder.

M44: Zorlandığı bir durumla karşılaştığında pes etmeden devam eder.

M50: Tartışma ve çatışma sonrasında gönül alır/nazikçe yeniden ilişki kurar.

M55: Teknolojik araçları basit kelimelerle tanımlar ve hakkında bilgi verir.

M:56 Teknolojik (telefon, tablet, bilgisayar) cihazları nasıl kullanabileceğini sorar ve bağımsız bir şekilde kullanır.

\section{Doğrulayıcı Faktör Analizine İlişkin Bulgular}

5-6 Yaş Çocukları İçin 21. Yy Becerileri (DAY-2) Ölçeğinin açımlayıcı faktör analizi sonucu elde edilen yapısını test etmek için birinci ve ikinci düzey doğrulayıcı faktör analizleri gerçekleştirilmiştir. DFA yapılması amacıyla nihai ölçeğin 33 maddeli ve üç faktörlü yapısını test etmek amacıyla araştırmaya katılmayan 305 çocuktan oluşan yeni bir katılımcı grup belirlenmiştir. Analizler sonucunda verilerin normal dağıldığı tespit edilmiştir. İlk DFA'da ölçeğin üç boyutlu hali test edilmiş (birinci düzey DFA-first order CFA), ikinci DFA'da ise, üç boyutun da birleşip tek boyutu ölçtüğü (ikinci düzey DFA-second order CFA) hali test edilmiştir. Her iki farklı DFA'ya ilişkin bulgular aşağıda verilmiştir.

\section{Birinci Düzey DFA'ya İlişkin Bulgular}

Birinci düzey DFA analizi sonucunda elde edilen standartlaştırılmış faktör yükleri madde ortalamaları, standart sapmaları ve her bir maddenin düzeltilmiş madde-toplam korelasyonları (nokta 
çift serili korelasyon) Tablo 3'de verilmiştir. Tablo 3'de verilen değerler incelendiğinde maddelerin faktör yükleri. 63 ile .89 arasında değiştiği gözlenmektedir. Benzer şekilde maddelerin madde-toplam korelasyonları ise .57 ile . 81 arasında değiştiği saptanmıştır. Ölçeğim üç boyutlu yapısına uygun olarak hazırlanan ve madde 1 ve madde iki arasında, madde 16 ve madde 17 arasında, madde 20 ve madde 21 arasında ve son olarak madde 21 ve madde 22 arasında yapılan bağlamalar sonucuna ilişkin istatistikleri $X^{2} / \mathrm{sd}=2.37, \mathrm{RMSEA}=.07, \mathrm{CFI}=.91, \mathrm{TLI}=.90, \mathrm{SRMR}=.04$ olarak bulunmuştur. Analizler sonucunda elde edilen bu bulguların alanyazındaki öneriler doğrultusunda ölçeğin kabul edilebilir değerlere sahip olduğu söylenebilir (Brown, 2006; Kline, 2005; Tabachnick ve Fidell, 2015). Maddeler arasında yapılan bağlamalar hem teorik olarak hem de istatistiksel olarak ilgili maddeler arasındaki uyumdan kaynaklandığı düşünülerek yapılmıştır.

Tablo 3. DAY-2 Ölçeğine İlişkin Madde İstatistikleri

\begin{tabular}{|c|c|c|c|c|}
\hline Madde & Faktör Yükü & Ortalama & Standart Sapma & Madde-Toplam Korelasyonu \\
\hline M1 & 0,76 & 2,77 & 0,89 & 0,77 \\
\hline M2 & 0,72 & 2,97 & 0,85 & 0,72 \\
\hline M3 & 0,81 & 2,98 & 0,86 & 0,78 \\
\hline M4 & 0,82 & 2,94 & 0,94 & 0,77 \\
\hline M5 & 0,76 & 3,04 & 0,85 & 0,73 \\
\hline M6 & 0,81 & 2,89 & 0,88 & 0,78 \\
\hline M7 & 0,80 & 2,84 & 0,90 & 0,77 \\
\hline M8 & 0,80 & 2,76 & 0,97 & 0,74 \\
\hline M9 & 0,79 & 2,86 & 0,86 & 0,74 \\
\hline M10 & 0,82 & 2,87 & 0,90 & 0,77 \\
\hline M11 & 0,77 & 2,91 & 0,92 & 0,75 \\
\hline M12 & 0,84 & 2,87 & 0,90 & 0,80 \\
\hline M13 & 0,83 & 2,75 & 0,92 & 0,79 \\
\hline M14 & 0,85 & 2,82 & 0,90 & 0,81 \\
\hline M15 & 0,85 & 2,81 & 0,90 & 0,80 \\
\hline M16 & 0,63 & 3,23 & 0,83 & 0,57 \\
\hline M17 & 0,72 & 3,16 & 0,83 & 0,66 \\
\hline M18 & 0,69 & 2,90 & 0,88 & 0,62 \\
\hline M19 & 0,70 & 3,08 & 0,85 & 0,64 \\
\hline M20 & 0,75 & 2,91 & 0,89 & 0,71 \\
\hline M21 & 0,76 & 2,83 & 0,89 & 0,74 \\
\hline M22 & 0,81 & 2,95 & 0,88 & 0,75 \\
\hline M23 & 0,77 & 3,07 & 0,86 & 0,70 \\
\hline M24 & 0,80 & 2,88 & 0,86 & 0,77 \\
\hline M25 & 0,79 & 2,85 & 0,87 & 0,78 \\
\hline M26 & 0,66 & 3,06 & 0,89 & 0,64 \\
\hline M27 & 0,71 & 3,00 & 0,79 & 0,68 \\
\hline M28 & 0,77 & 2,98 & 0,81 & 0,71 \\
\hline M29 & 0,89 & 2,85 & 0,86 & 0,70 \\
\hline M30 & 0,81 & 2,73 & 0,87 & 0,69 \\
\hline M31 & 0,88 & 2,76 & 0,88 & 0,65 \\
\hline M32 & 0,85 & 2,62 & 0,96 & 0,68 \\
\hline M33 & 0,81 & 2,84 & 0,93 & 0,63 \\
\hline
\end{tabular}

M1,M2, M3, M4, M5, M6, M7, M8, M9, M10, M11, M12, M13, M14, M15 Öğrenme ve Yenilik Becerileri (4Cs); M16, M17, M18, M19, M20, M21, M22, M23, M24, M25, M26, M27, M28, Yaşam ve Kariyer Becerileri; M29, M30, M31, M32, M33 Bilgi-Medya ve Teknoloji Becerileri 
Açıklanan varyans oranları incelendiğinde; Öğrenme ve Yenilik Becerileri (4Cs) boyutunun .45 (\%45), Yaşam ve Kariyer Becerileri boyutunun 27 (\%27) ve Bilgi, Medya ve Teknoloji Becerileri .58 (\%58) kısımların açıklandığı saptanmıştır. Ayrıca tüm faktör yükleri ve açıklanan varyans oranlarının .01 düzeyinde istatistiksel olarak anlamlı olduğu görülmektedir. Benzer olarak her bir boyutun Cronbach alpha değerleri hesaplanmış ve Öğrenme ve Yenilik Becerileri (4Cs) boyutu için .96, Yaşam ve Kariyer Becerileri boyutunun .94 ve Bilgi, Medya ve Teknoloji Becerileri 92 olarak hesaplanmıştır. Ölçeğin Tek boyutlu halinin Cronbach alpha değeri ise .97 olarak saptanmıştır. Ayrıca her bir boyuta ilişkin gözlemlenen toplam puanlar arasındaki korelasyonlar .72 ile .87 arasında değişmekte olup Tablo 4'te verilmiştir.

Tablo 4. Boyutlardan Alınan Gözlemlenen Toplam Skorlar Arasındaki Korelasyonlar

\begin{tabular}{|c|c|c|c|}
\hline Boyut & $\begin{array}{l}\text { Öğrenme ve Yenilik } \\
\text { Becerileri (4Cs) }\end{array}$ & $\begin{array}{c}\text { Yaşam ve Kariyer } \\
\text { Becerileri }\end{array}$ & $\begin{array}{l}\text { Bilgi, Medya ve Teknoloji } \\
\text { Becerileri }\end{array}$ \\
\hline Öğrenme ve Yenilik & 1 & & \\
\hline Becerileri (4Cs) & & & \\
\hline $\begin{array}{l}\text { Yaşam ve Kariyer } \\
\text { Becerileri }\end{array}$ & $0.87 *$ & 1 & \\
\hline $\begin{array}{l}\text { Bilgi, Medya ve Teknoloji } \\
\text { Becerileri }\end{array}$ & $0.74 *$ & $0.72 *$ & 1 \\
\hline
\end{tabular}

DAY-2 ölçeğin gizil boyutlar arasındaki korelasyonlar ise .63 ile .89 arasında değişmekte olup Şekil 2'de birinci düzey 3 boyutlu DFA modeli üzerinde gösterilmiştir. Burada ölçeğin tek düzeyli faktör yapısının uygun bir şekilde çalıştığı görülmektedir. Bu durumun her bir boyutun ayrı ayrıda kullanılabileceğini göstermektedir (Brown, 2006; Hu ve Bentler,1999; Kline, 2005; Schreiber, Nora, Stage, Barlow, ve King, 2006).

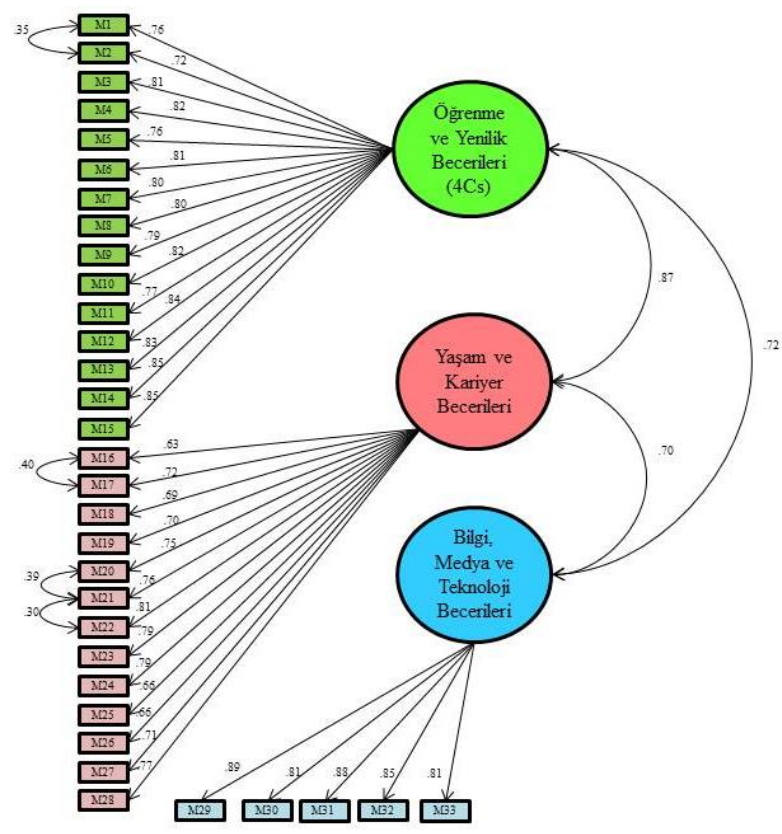

Şekil 2. DAY-2 Ölçeğinin Tek Düzeyli Faktör Yapısı 


\section{İkinci Düzey DFA’ya İlişkin Bulgular}

İkinci düzey DFA analizi, belirlenen faktörlerin çocuklarda 21. yüzyıl becerilerini ne derece ölçtügünü belirlemek amaciyla oluşturulmuştur. Şekil 3'de DFA analizine ilişkin elde edilen standartlaştırılmış faktör yükleri verilmiştir.

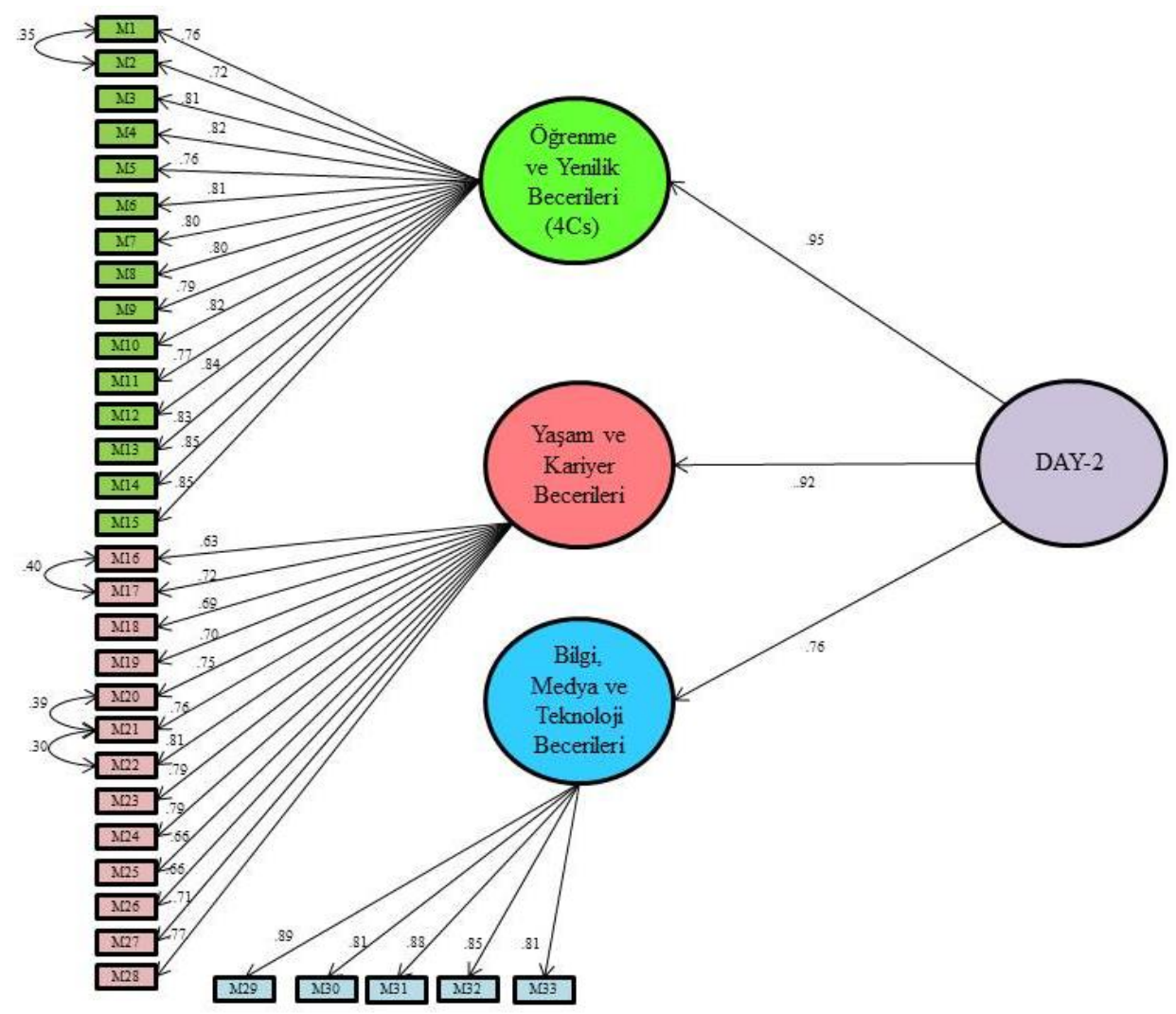

Şekil 3. DAY-2 Ölçeğinin İkinci Düzey Faktör Yapısı

Şekil 3 incelendiğinde, ölçekte yer alan madde yükleri .63 ile .89 arasında değiştiği gözlenmektedir. DAY-2 ölçeğinin ikinci düzey faktör yükleri incelendiğinde, faktör yüklerinin .76 ile .95 arasında değişti gözlenmektedir. Ölçeğin iki düzeyli yapısına ilişkin model-veri uyum istatistikleri $\mathrm{X} 2 / \mathrm{sd}=2.66, \mathrm{RMSEA}=.07, \mathrm{CFI}=.91, \mathrm{TLI}=.90, \mathrm{SRMR}=.45$ olarak bulunmuş olup bu değerlerin alan yaında yer alan değerlere göre modelin iyi bir şekilde uyum sağladığını göstermektedir (Brown, 2006; Hu ve Bentler,1999; Kline, 2005; Schreiber, vd., 2006; Tabachnick ve Fidell, 2015). Ölçekte 3 boyutun ölçtüğü genel boyut "5-6 Yaş Çocukları için 21. yy Becerileri Ölçeği (DAY-2)" olarak adlandırılmış olup genel boyutun açıklanan varyans oranları .01 düzeyinde istatistiksel olarak anlamlı bulunmuştur. Tüm faktör yükleri ve açıklanan varyans oranları .01 düzeyinde istatistiksel olarak anlamlıdır. İç tutarlılık katsayısı incelendiğinde DAY-2 ölçeğinin genel boyutun Cronbach alfa değeri .97 şeklinde yüksek bir değere sahip olduğu saptanmıştır (Peterson, 2000). 


\section{SONUÇ VE ÖNERILER}

Bu çalışmada 5-6 yaş grubu okul öncesi dönem çocuklarının 21. yüzyıl becerilerine yönelik ölçek geliştirme çalışması yapılması amaçlanmıştır. Bu amaç doğrultusunda hazırlan 56 maddelik dörtlü likert şeklinde hazırlanan ölçek, 622 okul öncesi dönem çocuğuna uygulanmış ve elde edilen veriler Mplus ve SPSS 23 programı uygulanarak AFA ve DFA analizleri yapılarak ölçeğin son hali verilmiştir.

5-6 yaş grubu okul öncesi dönem çocuklarının 21. yüzyıl becerilerini ölçen DAY-2 ölçeği üç (3) alt boyutu olan 33 maddeden oluşan dörtlü likert tipinde geliştirilen bir ölçektir. Ölçeğin AFA analizinden elde edilen KMO değeri.96 olarak hesaplamış ve Barlett test değeri 17415,15, p<,001 olarak bulunmuş ve değişkenlerin faktörlenebilir derecede olduğu ortaya saptanmıştır. Ölçeğin faktörlü yapısına ait AFA sonuçlarına göre $X^{2} / \mathrm{sd}=2.39, \mathrm{RMSEA}=.06, \mathrm{CFI}=.95$, TLI $=.94$ ve $\mathrm{SRMR}=$ .04 olarak bulunmuştur. AFA sonuçlarına göre .62 ile . 97 arasında değiştiği saptanmıştır. Tabachnick ve Fidell (2015) faktör yükünün .55 ile .62 arasında olmasının "iyi”.63 ile .70 arasında olmasını "çok iyi” ve .71 ve üzerinde olmasını "mükemmel" olarak değerlendirmektedir. Bu durumda ölçeğin elde edilen faktör yüklerinin çok iyi bir durumda olduğu söylenilebilir.

Üç faktörlü olarak belirlenen ölçeğin birinci ve ikinci düzey doğrulayıcı faktör analizi (DFA) aracılığıyla ayrı ayrı test edilmiştir. Birinci düzey DFA sonuçlarına göre maddelerin faktör yükleri .68 ile .94 arasında değiştiği gözlenmektedir. Ölçeğim üç boyutlu yapısına uygun olarak hazırlanan ve madde 1 ve madde 2 arasinda, madde 16 ve madde 17 arasında, madde 20 ve madde 21 arasinda ve son olarak madde 21 ve madde 22 arasında yapılan bağlamalar sonucuna ilişkin istatistikleri $X^{2} / \mathrm{sd}=$ 2.66, RMSEA $=.07, \mathrm{CFI}=.91, \mathrm{TLI}=.90, \mathrm{SRMR}=.04$ olarak bulunmuştur. İkinci düzey DFA analizi ölçekte yer alan madde yükleri .63 ile .89 arasında değiştiği ve ölçeğin iki düzeyli yapısına ilişkin model-veri uyum istatistikleri $X^{2} / \mathrm{sd}=2.66, \mathrm{RMSEA}=.07, \mathrm{CFI}=.91, \mathrm{TLI}=.90, \mathrm{SRMR}=.45$ olarak saptanmıştır. Bu durumda ölçeğin hem 3 boyutlu hem de tek boyutlu yapısının uyum değerlerinin çok iyi olduğu söylenebilir (Brown, 2006; Kline, 2005; Tabachnick ve Fidell, 2015).

Ölçeğin her bir alt boyutuna ait Cronbach alpha değerleri SPSS 23 kullanılarak hesaplanmış ve Öğrenme ve Yenilik Becerileri (4Cs) boyutu için .96, Yaşam ve Kariyer Becerileri boyutunun .94 ve Bilgi, Medya ve Teknoloji Becerileri .92 olarak hesaplanmıştır. Ölçeğin Tek boyutlu halinin Cronbach alpha değeri ise .97 olarak saptanmıştır. Kayış, (2014) güvenirlik katsayısı olan Cronbach alpha değerinin .80 ve üzeri olmasının ölçeğin yüksek derece güvenirliğe sahip olduğunu belirtmiştir. $\mathrm{Bu}$ durumda ölçeğin hem alt boyutlarının hem de tek düzeyli yapısının yüksek derecede iç tutarlığa sahip olduğu söylenebilir.

5-6 yaş grubu okul öncesi dönem çocuklarının 21. yüzyıl becerilerini ölçen DAY-2 ölçeğine ilişkin olarak literatüre bakıldığında Çevik ve Şentürk (2019) 15-25 yaş çocuk ve gençlerle yapmış “çok boyutlu 21. yy becerileri ölçeği” 41 maddeden oluşan beş (5) boyutlu bir ölçek olarak ortaya 
koymuştur. Çevik ve Şentürk (2019) yapmış oldukları çalışmada geliştikleri ölçeğin Cronbach alpha değerini .86 gibi yüksek bir skor olarak belirtmişlerdir. Araştırmacılar geliştirmiş oldukları ölçekte 5'li likert tipinde değerlendirme kıstası belirlemişlerdir. DAY-2 ölçeğinde yer alan 33 madde ve 4'lü likert tipinin kullanılması, ölçeğin okul öncesi dönem çocuklarına hitap etmesinden dolayı uzmanların görüşleri doğrultusunda belirlenmiştir.

Ayrıca ölçekte yer alan katılımcılara ait demografik bilgiler incelendiğinde, çocukların cinsiyet bakımından birbirine yakın sayılarda olması, anne ve baba mesleki durumlarının farklı meslek gruplarından olması (Ev Hanımı, Öğretmen, Polis, İşçi, Memur, Esnaf, Güvenlik görevlisi, Tamirci, İşsiz, Şoför, Askeri Personel, Çiftçi, Doktor, Akademisyen, vb...) çalışmada elde edilen verilerin kapsayıcılığını göstermektedir.

Buradan elde edilen sonuçlar doğrultusunda 5-6 Yaş Çocukları İçin 21.Yüzyıl Becerileri (DAY2) Ölçeği geçerli ve güvenilir bir ölçek olarak ortaya konulmuştur. Araştırmacılar bu ölçeği kullanarak farklı değişkenlere bağlı çalışmalar yürütebilir. Öğretmenler, ölçeği kullanarak sınıfında bulunan 5-6 yaş çocuklarının 21.Yy becerilerini tespit edebilir ve geliştirebilir. Türkiye genelinde 5-6 yaş çocuklarında bu ölçek uygulanarak, çocukların 21.Yy becerileri belirlenebilir ve bu bulgular doğrultusunda eğitim politikalarına yön verilerek ve mevcut eğitim programları güncellenerek, PISA Eğitim Raporu gibi uluslararası öğrenci değerlendirme platformlarında daha iyi seviyeler elde edilebilir.

Sonuç olarak bu çalışmada geçerliği ve güvenirliği test edilmiş, 5-6 yaş grubu okul öncesi dönem çocuklarının 21. yüzyıl becerilerini ölçen, üç (3) alt boyutu olan, 33 maddeden oluşan dörtlü (4) likert tipinde bir ölçek geliştirilmiştir.

\section{KAYNAKÇA}

Akgündüz, D., \& Akpınar, B. C. (2018). Okul öncesi eğitiminde fen eğitimi temelinde gerçekleştirilen STEM uygulamalarının öğrenci, öğretmen ve veli açısından değerlendirilmesi. Yaşadıkça Ĕgitim Dergisi,32 (1).

Ananiadou, K. ve Claro, M. (2009). 21st century skills and competences for new millennium learners in OECD countries. OECD Education Working Papers: OECD Publishing. 25 Ocak 2019 tarihinde http://www.oecdilibrary.org/education/21 st-century-skills-and-competences-for-newmillenniumlearners-in-oecd-countries_218525261154 adresinden edinilmiştir.

Aygün, Ş. S., Atalay, N., Kılıç, Z., \& Yaşar, S. (2016). Öğretmen adaylarına yönelik 21. yüzyıl becerileri yeterlilik algıları ölçeğinin geliştirilmesi: Geçerlik ve güvenirlik çalışması. Pamukkale Üniversitesi Eğitim Fakültesi Dergisi, 40(40), 160-175.

Beers, S. Z. (2011). 21st century skills Preparing students for their future Retrieved from https://www.mheonline.com/mhmymath/pdf/21st_century_skills.pdf

Brown, S. (2018). Best Practices in 21st Century Learning Environments: A Study of Two P21 Exemplar Schools. (Doktora tezi), Brandman, California. 
Brown, T. (2006). Confirmatory factor analysis for applied research. Newyork: Guildford Publications, Inc.

Büyüköztürk, Ş. (2012). Sosyal bilimler için veri analizi el kitabı (17. Bask1). Ankara: PegemA Yayıncılık.

Büyüköztürk. Ş. (2002). Faktör analizi: Temel kavramlar ve ölçek geliştirmede kullanımı. Eğitim Yönetimi Dergisi, 32, 470-483.

Ceylan, Ş. (2014). Okul öncesi öğretmenlerinin dünya vatandaşlğ̆1 eğitimi ile ilgili görüşleri. Kuramsal Ĕ̈itimbilim Dergisi, 7(1), 78-93.

Çevik, M. \& Şentürk C. (2019). Multidimensional 21th century skills scale: Validity and reliability study. Cypriot Journal of Educational Sciences. 14(1), 011-028.

Çil, E. (2018). Okul öncesi dönemde STEM eğitimi. Pegem Atıf İndeksi, 457-483.

Çokluk, O., Şekercioğlu, G. \& Büyüköztürk, S. (2010). Sosyal bilimler için çok değişkenli istatistik. Ankara, Türkiye: Pegem Akademi.

Çokluk, Ö., Şekercioğlu, G., \& Büyüköztürk, Ş. (2012). Sosyal bilimler için çok değişkenli istatistik SPSS ve Lisrel uygulamaları (3rd Ed.). Ankara: Pegem Akademi.

EnGauge. (2003). En Gauge 21st Century Skills. Retrieved from https://www.cwasd.k12.wi.us/highschl/newsfile1062_1.pdf

Gelen, İ. (2017). P21-Program ve öğretimde 21. yüzyıl beceri çerçeveleri (ABD Uygulamaları). Disiplinlerarası Ĕgitim Araştırmaları Dergisi, 1(2), 15-29.

George, D. ve Mallery, P. (2001). SPSS for Windows step by step: A simple guide \& reference 1.0 uptdate, (3rd.ed.), Allyn and Bacon Publications.

Gökçe, E. (2000). Yirmi birinci yüzyılın öğretmeni. Çağdaş Eğitim Dergisi, 270, 21-26.

Göksün, D. O., \& Kurt, A. A. (2017). Öğretmen adaylarının 21. yy. öğrenen becerileri kullanımları ve 21. yy. öğreten becerileri kullanımları arasındaki ilişki. Eğitim ve Bilim, 42(190).

Gray, A. (2016). The 10 skills you need to thrive in the Fourth Industrial Revolution. Paper presented at the World Economic Forum. Obtenida el.

Harari, Y. N. (2018). 21.yüzyll için 21 ders (S. Siral, Trans.). İstanbul: Kolektif Kitap.

Herring, D. F. ve Notar, C. E. (2011). Show what you know: ePortfolios for 21 st century learners. College Student Journal, 45(4), 786-792.

Hu, L. T.,\& Bentler, P. M. (1999). Cutoff criteria for fit indexes in covariance structural analysis: Conventional criteria versus new alternatives. Structural Equation Modeling, 6, 1-55.

Kayış, A. (2014). Güvenirlik analizi. Şeref Kalaycı (Ed.), SPSS uygulamalı çok değişkenli istatistik teknikleri içinde (s. 404-409). Ankara: Asil Yayın Dă̆ııım.

Kenan, S. (2005). 21. yy'da Türkiye'de öğretmen olmak (EBSAD - Öğretmenlik Vizyon Programı Seminer Notlarl). Paper presented at the EBSAD - Öğretmenlik Vizyon Program1 http://www.ebsad.org/img/20140407_2541009784.pdf

Kline, B. R. (2005). Principles and practice of structural equation modeling (2nd Edt.). Newyork London: The Guilford Press.

Kline, P. (1994). An easy guide to factor analysis. New York, NY: Routledge. 
Lamb, S., Maire, Q., \& Doecke, E. (2017). Key Skills for the 21st Century: an evidence-based review. Retrieved from https://education.nsw.gov.au/our-priorities/innovate-for-the-future/education-for-achanging-world/research-findings/future-frontiers-analytical-report-key-skills-for-the-21stcentury/Key-Skills-for-the-21st-Century-Executive-Summary.pdf

Milli Eğitim Bakanlı̆̆ı Temel Eğitim Genel Müdürlüğ̈̈-MEB (2013). Okul Öncesi Eğitim Program1, Ankara.

Muthén, L. K., ve Muthén, B. O. (1998-2012). Mplus user's guide. Seventh Edition. Los Angeles, CA: Muthén \& Muthén.

National Research Council. (2011). Assessing 21st century skills: Summary of a workshop: National Academies Press.

Özçelik, A., \& Akgündüz, D. (2018). Üstün/özel yetenekli öğrencilerle yapılan okul dışı STEM eğitiminin değerlendirilmesi. Trakya Üniversitesi Eğitim Fakültesi Dergisi, 8(2), 334-351.

P21 (Partnership21). (2015). P21 framework definitions. 13 Kas1m 2019 tarihinde http://www.p21.org/storage/documents/docs/P21_Framework_Definitions_Ne w_Logo_2015.pdf adresinden edinilmiştir.

P21. (2018a). Assessment: A 21st Century Skills Implementation Guide. Retrieved from http://www.p21.org/storage/documents/p21-stateimp_assessment.pdf

P21. (2018b). Showcasing the Nation's Best in 21st Century Learning. Retrieved from http://www.p21.org/storage/documents/exemplars/P21_Patterns_of_Innovation_Final.pdf

Partnership for 21 st Century Skills (P21). (2003). Learning for the 21st century: A report and mile guide for 21st century skills. Retrieved from Washington, D.C.: https://files.eric.ed.gov/fulltext/ED480035.pdf

Partnership for 21st Century Skills. (2009). Framework for 21st century learning. Retrieved from http://www.p21.org/our-work/p21-framework

Pedro, F. (2006). The new millennium learners: Challenging our views on ICT and learning. 3 Şubat 2019 tarihinde http://www.oecd.org/edu/ceri/38358359.pdf adresinden edinilmiştir.

Peterson, R. (2000). A meta-analysis of variance accounted for and factor loadings in exploratory factor analysis. Marketing Letters, 11, 261-275.

Prensky, M. (2001a). Digital natives, digital immigrants. MCB University Press, 9(5), 1-6.

Prensky, M. (2001b). Digital natives, digital immigrants, part II: Do they really think differently? $N C B$ University Press, 9(6), 1-6.

Prensky, M. (2003). Has growing up digital and extensive video game playing affected younger military personnel's skill sets?. I/ITSEC 2003'te sunulmuş bildiri.

Schreiber, J. B., Nora, A., Stage, F. K., Barlow, E. A., \& King, J. (2006). Reporting structural equation modeling and confirmatory factor analysis results: A review. The Journal of educational research, 99(6), 323-338

Şahin, M. C. (2010). Eğitim fakültesi öğrencilerinin yeni binyllın öğrencileri (OECDNew millenium learners) ölçütlerine göre değerlendirilmesi. Yayınlamamış doktora tezi, Anadolu Üniversitesi Eğitim Bilimleri Enstitüsü, Eskişehir. 
Şahin, M.G., ve Boztunç Öztürk, N. (2018). Eğitim alanında ölçek geliştirme süreci: Bir içerik analizi çalışması. Kastamonu Eğitim Dergisi, 26(1), 191-199. doi:10.24106/kefdergi.375863

Tabachnick, B. G. ve Fidell, L. S. (2015). Çok değişkenli istatistiklerin kullanımı. (M. Baloğlu, Çev. Ed.). Ankara: Nobel Akademik Yayıncıllk

Tavşancıl, E. (2006). Tutumların Ölçülmesi ve SPSS ile Veri Analizi, Ankara: Nobel Yayın Dağıtım.

Tavşancıl, E. (2014). Tutumların ölçülmesi ve SPSS ile veri analizi. Ankara, Turkey: Nobel Akademi Publishing.

Tezbaşaran, A.A. (1996). Likert tipi ölçek geliştirme kılavuzu. Ankara: TPD Yayınları.

Thomas, K. S. (2014). The effectiveness of select upward bound programs in meeting the needs of 21 st century learners in preparation for college readiness.

Tuğluk, M. N., \& Özkan, B.(2019). MEB 2013 Okul Öncesi Eğitim Programının 21. Yüzyıl Becerileri Açısından Analizi. Temel Ĕgitim, 1(4), 29-38.

Uğraş, M. (2017). Okul Öncesi Öğretmenlerinin STEM Uygulamalarına Yönelik Görüşleri. Eğitimde Yeni Yaklaşımlar Dergisi. 1(1)s. 39-54.

Veneziano L. ve Hooper J. (1997). "A method for quantifying content validity of healthrelated questionnaires". American Journal of Health Behavior, 21(1):67-70.

Voogt, J., \& Roblin, N. P. (2012). A comparative analysis of international frameworks for 21 st century competences: Implications for national curriculum policies. Journal of curriculum studies, 44(3), 299-321.

Williams, C., Gannon, S. ve Sawyer, W. (2013). A genealogy of the 'future': Antipodean trajectories and travels of the '21st century learner'. Journal of Education Policy, 28(6), 792-806.

Woods-Groves, S. (2015). The human behavior rating scale-brief: A tool to measure 21st century skills of K-12 learners. Psychological Reports: Measure \& Statistics, 116(3), 769-796.

Yalçın, V. (2019). Kuram, öğretim modeli, uygulama yöntemi ve çalışma planı bağlamında STEM. Akademik Sosyal Araştırmalar Dergisi, Yll: 7, Sayl: 90, Mart 2019, s. 356-368

Yıldırım, C. (1999). Eğitimde Ölçme ve Değerlendirme. Ankara: ÖSYM yayınları.

Young, J. S. (2012). Linking learning: Connecting traditional and media literacies in 21st century learning. Journal of Media Literacy Education, 4(1), 70-81.

North Central Regional Educational Laboratory and the Metiri Group-NCREL (2003). 21st Century Skills: Literacy in the Digital Age. http://pict.sdsu.edu/engauge21st.pdf (Erişim tarihi: 05.02.2020). 


\section{EXTENDED SUMMARY}

\section{Introduction and Significance}

As a result of social, economic, political and especially technological changes in the $21 \mathrm{st}$ century and depending on these developments, some changes in the qualities of the individuals needed are noticeable. Therefore, these developments in different areas affect the education systems that will enable the emergence of the qualified individuals needed and may make it necessary for the countries to make some changes in the education policies (Kenan, 2005). While it was seen that accessing information was very important in the past, it has become more important skills for the individual to understand, use, distinguish important information and relate it to other information (Harari, 2018).

It started to emerge in studies related to the skill (Gökçe, 2000; Pedro, 2006; Prensky, 2001a; 2001b; 2003). In this direction, when the international literature is examined, the 21st-century information and media experts of Mardis and Dickinson (2009). 21st Century, defined by Herring and Notar (2011) and Partnership and EnGuage. Young (2012) tried to reveal the link between learner skills and media literacy, Williams, Gannon and Sawyer (2013) looked at the technology and media usage in the context of Australia in the 21st century. The research tried to determine their learner skills and Woods-Grooves (2015) 21st century. Studies aiming to determine the factors that affect the behavior of their learners are outstanding.

The development of 21 st century skills for young children is very important for their future. One of the important points in developing these skills in individuals is that they are supported in other educational levels starting from the preschool period. However, one of the important factors in acquiring and developing these skills is to measure and control these skills periodically with the right measurement tools and to give correct outputs to family, teachers, and education programmers. The literature showed that there was not any scale for the scopes of early childhood children's $21^{\text {st }}$ century skilss. However there were some studies related with at the level of high school and university (Aygün, Atalay, K1lı̧ \& Yaşar, 2016; Çevik and Şentürk 2019). In this context, the 21st century of preschool children. "21st Century for 5-6 Years Old Children (DAY-2)", which was made to determine their skills. The study is considered to be very important as it will close the gap in the literature.

\section{Method}

This study is a scale development study. In this process, this scale, which is oriented towards 21 st-century skills of children, was created by paying attention to the scale development processes. 640 60-72-month-old children participated in the study by 36 different teachers in 12 different kindergartens. In the study, 18 children whose teachers gave incomplete information were not included in the analysis and data on 622 children in total were included in the analysis. Results 


\section{Conclusion and Suggestions}

It is also observed that the item loads in the scale vary between .68 and .95 . When the second level factor analyzes loads of the scale, it is observed that the factor loads varied between .78 and .95 . Model-data fit statistics regarding the two-level structure of the scale were found as X2 / sd $=2.37$, RMSEA $=.06, \mathrm{CFI}=.97, \mathrm{TLI}=.97, \mathrm{WRMSR}=1.138$, and these values show that the model fits well. The overall dimension measured by 3 dimensions Life and Career Skills, Learning and Innovation Skills (4Cs), Information-Media and Technology Skills was named as DAY-2 and the explained variance rates of the overall dimension were found statistically significant at the .01 level. When the internal consistency coefficient is analyzed, it is determined that the DAY-2 general dimension has a high value of Cronbach alpha value .97. In this study, it is aimed to develop a scale development study for 21 st-century skills of preschool children aged 5-6. The scale prepared in the form of a 56-point four-point Likert prepared for this purpose was applied to 622 preschool children and the data obtained were finalized by applying AFA and DFA analysis by applying the Mplus and SPSS 23 programs. DAY-2 scale, which measures 21st-century skills of preschool children aged 5-6, is a fourpoint Likert type scale consisting of 33 items with three (3) sub-dimensions. The KMO value obtained from the AFA analysis of the scale was calculated and calculated as .96, and the Barlett test value was found to be 17415.15, p <, 001, and it was revealed that the variables were factorial. According to the AFA results of the factor structure of the scale, $\mathrm{X} 2 / \mathrm{sd}=2.39, \mathrm{RMSEA}=.06, \mathrm{CFI}=.95, \mathrm{TLI}=.94$ and SRMR $=.04$. According to AFA results with .62. It was found to vary between 97 .

The scale, which was determined as three-factor, was tested separately through the first and second level confirmatory factor analysis (CFA). According to the first level CFA results, the factor loads of the items varied between .68 and .94 . Statistics on the result of the binding results between item 1 and item 2, item 16 and item 17, item 20 and item 21, and finally item 21 and item 22 in accordance with the three-dimensional structure of my scale X2 / df $=2.37$, RMSEA $=$ It was found as $.06, \mathrm{CFI}=.97, \mathrm{TLI}=.97, \mathrm{WRMSR}=1.138$. Item loads in the second level DFA analysis scale varies between .68 and .95 and model-data fit statistics regarding the two-level structure of the scale X2/ sd $=2.37, \mathrm{RMSEA}=.06, \mathrm{CFI}=.97, \mathrm{TLI}=.97, \mathrm{WRMSR}=$ It was determined as 1.138. In this case, it can be said that both the 3-dimensional and one-dimensional structure of the scale is very good (Brown, 2006; Kline, 2005; Tabachnick \& Fidell, 2015). Cronbach alpha values for each subdimension of the scale were calculated using SPSS 23 and .96 for the Learning and Innovation Skills (4Cs) dimension, .94 for the Life and Career Skills dimension and the Information, Media and Technology Skills .92. The Cronbach alpha value of the one-dimensional version of the scale was found to be .97 . As a results of the study, it was revealed that DAY-2 is a valid and reliable assessment tool for preschool children's $21^{\text {st }}$ century skills. 